\section{Replacement of Adrenaline and Noradrenaline in the Adrenal Gland of the Rat, following Depletion and Redepletion with Reserpine}

Is a previous communication ${ }^{1}$, we showed that reserpine causes a similar percentage loss of adrenaline and noradrenaline from the adrenal glands of the rat. Recovery of the catechol amines was slow, the amine content returning to normal within 21 days. The adrenaline content gradually returned to the control value, whereas the noradrenaline content first increased rapidly to a level well above normal at 7 days before falling to the control value.

To determine whether or not the recently replaced amines are bound in the medullary cells in a different manner from the amines that are not released during depletion, it was decided to redeplete the glands at 7 and 21 days. Redepletion at 7 days would detect any difference in tho sensitivity to reserpine of the recently replaced amines and redepletion at 21 days would reveal whether or not the glands had, at that time, returned to normal with respect to their sensitivity to further reserpine treatment.

In this series of experiments groups of 5 male albino rats weighing $150-190 \mathrm{gm}$. were used. The treatment they received and the schedule of killing are shown in Table 1. Four 7-day and two 21-day redepletion experiments were performed. In all 88 groups of 5 rats were used. Each test group had its own control group also of 5 rats. In every instance except the 10-day point in the 7-day redepletion experiments, the control groups consisted of glands from rats given the reserpine solvent only. The control group for the 10-day point was obtained from the glands of rats given reserpine on days 0,1 and 2 and killed on day 10 (Table 1). This represents the amine content that the redepleted group would have attained if it had not been further treated with reserpine. Subsequent to this 10-day point the controls were the normal solvent. injected rats, because it was found that the relative amounts of adrenaline and noradrenaline following redepletion were very similar to the amounts following the initial depletion. The glands were extracted with $N / 10$ hydrochloric acid and assayed biologically as described previously ${ }^{1}$.

As can be seen from Fig. 1, redepletion at 7 days caused a preferential loss of noradrenaline, the newly replaced amine thus appearing more susceptible to the action of reserpine than that remaining after the initial depletion. The subsequent recovery of the noradrenaline content was similar to the initial recovery, with a peak of noradrenaline occurring 7 days after the beginning of redepletion. The noradrenaline content was still slightly raised above the

\begin{tabular}{|c|c|c|c|c|c|c|c|}
\hline \multirow{3}{*}{$\frac{\text { Group }}{\text { Depletion }}$} & \multicolumn{6}{|c|}{ Day } & \multirow{3}{*}{$\begin{array}{r}\text { Killed } \\
3 \\
7 \\
14 \\
21\end{array}$} \\
\hline & \multicolumn{6}{|c|}{$\begin{array}{l}\text { Reserpine (1 mgm./kgm. } \\
\text { subcutaneously) administered }\end{array}$} & \\
\hline & $\begin{array}{l}0 \\
0 \\
0 \\
0\end{array}$ & $\begin{array}{l}1 \\
1 \\
1 \\
1\end{array}$ & $\begin{array}{l}2 \\
2 \\
2 \\
2\end{array}$ & & & & \\
\hline 7-day redepletion & $\begin{array}{l}0 \\
0 \\
0 \\
0\end{array}$ & $\begin{array}{l}1 \\
1 \\
1 \\
1\end{array}$ & $\begin{array}{l}2 \\
2 \\
2 \\
2 \\
\end{array}$ & $\begin{array}{l}7 \\
7 \\
7 \\
7 \\
\end{array}$ & $\begin{array}{l}8 \\
8 \\
8 \\
8 \\
\end{array}$ & $\begin{array}{l}9 \\
9 \\
9 \\
9 \\
9\end{array}$ & $\begin{array}{l}10 \\
14 \\
21 \\
28 \\
\end{array}$ \\
\hline 21-day redepletion & $\begin{array}{l}0 \\
0 \\
0 \\
0\end{array}$ & $\begin{array}{l}1 \\
1 \\
1 \\
1\end{array}$ & $\begin{array}{l}2 \\
2 \\
2 \\
2\end{array}$ & $\begin{array}{l}21 \\
21 \\
21 \\
21\end{array}$ & $\begin{array}{l}22 \\
22 \\
22 \\
22\end{array}$ & $\begin{array}{l}23 \\
23 \\
23 \\
23\end{array}$ & $\begin{array}{l}24 \\
28 \\
35 \\
42\end{array}$ \\
\hline
\end{tabular}

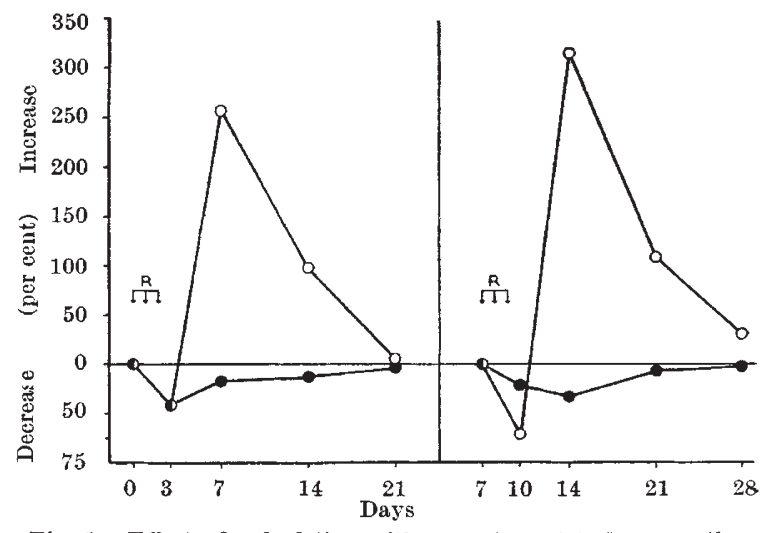

Fig. 1. Effect of redepletion with reserpine, at 7 days, on the adrenaline ( $)$ and noradrenaline ( $O$ ) content of rat adrenal

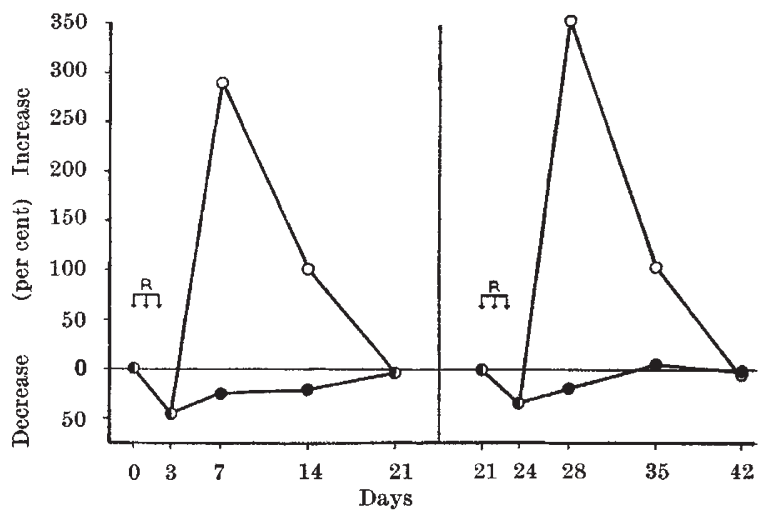

Fig. 2. Effect of redepletion with reserpine, at 21 days, on the adrenaline (O) and the noradrenaline $(O)$ content of rat adrenal
glands. Left, depletion; right, redepletion

control-level at 21 days. The replacement of adrenaline was similar to that which occurred in the initial depletion experiments.

Redepletion at 21 days (Fig. 2) caused losses of both adrenaline and noradrenaline similar to those which had occurred in the initial depletion experiments. The recovery of both amines was similar to that obtained initially with a peak of noradrenaline occurring at 28 days, that is, at 7 days following the beginning of redepletion.

Thus it appears that at 21 days the rat adrenal gland has recovered its normal catechol amine content. following a 50 per cent loss produced by reserpine. However, the preferential loss of noradrenaline occurring when redepletion occurred at 7 days resulted in the noradrenaline content of the glands being depleted to the same absolute amount as that following the initial depletion. Thus it seems possible that, under the experimental conditions described here, it is the newly synthesized noradrenaline that is released before there is time for it to be converted to adrenaline.

We wish to thank Ciba Laboratories, Ltd., for generous gifts of reserpine.

\section{B. A. Callingham} Monica ManN

Departmont of Pharmacology,

School of Pharmacy,

29-39 Brunswick Square,

London, W.C.1.

1 Callingham, B. A., and Mann, M., Nature, 181, 423 (1958). 